OPEN ACCESS

Edited by:

Janine Jason,

Jason and Jarvis Associates LLC,

USA

Reviewed by:

Sunil K. Jain,

University of Texas Medical Branch,

USA

Rinawati Rohsiswatmo,

Cipto Mangunkusumo Hospital,

Indonesia

*Correspondence:

Lennox Kenneth Archibald,

Infectious Disease Section, Malcom

Randall VA Medical Center, 1601 SW

Archer Road, Room A252-1,

Gainesville, FL 32608, USA

lennox.archibald@va.gov

Specialty section:

This article was submitted to Pediatric Infectious Diseases, a section of the

journal Frontiers in Pediatrics

Received: 24 March 2015

Accepted: 01 June 2015

Published: 02 July 2015

Citation:

Kalyantanda G, Shumyak $L$ and

Archibald LK (2015) Cronobacter

species contamination of powdered infant formula and the implications for neonatal health.

Front. Pediatr. 3:56.

doi: 10.3389/fped.2015.00056

\section{Cronobacter species contamination of powdered infant formula and the implications for neonatal health}

\author{
Gautam Kalyantanda ${ }^{1}$, Lyudmila Shumyak ${ }^{1}$ and Lennox Kenneth Archibald ${ }^{2 *}$ \\ ${ }^{1}$ Division of Infectious Diseases, College of Medicine, University of Florida, Gainesville, FL, USA, ${ }^{2}$ Malcom Randall VA Medical \\ Center, Gainesville, FL, USA
}

Cronobacter is a class of Enterobacteriaceae that cause infections in neonates, especially those born prematurely. Over $90 \%$ of these infections have been linked epidemiologically to powdered infant formula (PIF). Contamination of PIF can occur at manufacture, reconstitution, or storage of reconstituted product. Intrinsic properties that enable Cronobacter to cause disease include resistance to heat, ultraviolet radiation, oxygen radicals, stomach acids, and pasteurization; an ability to utilize sialic acid (a nutrition additive to PIF that facilitates the organism's growth and survival), and an exceptional affinity for biofilms in enteral feeding tubes. As part of ongoing endeavors to reduce the incidence of neonatal PIF-associated Cronobacter infections, the World Health Organization and the US Food and Drug Administration have established guidelines for PIF production, preparation for infant feeding, and storage of reconstituted product.

Keywords: Cronobacter, Enterobacter, sakazakii, powdered infant formula, neonatal mortality, necrotizing enterocolitis, neonatal sepsis, neonatal meningitis

\section{Introduction}

Cronobacter spp. belong to the Enterobacteriaceae family and are oxidase-negative, facultative anaerobic, Gram-negative bacilli with circumferentially arranged flagellae that render the microorganisms their motility $(1,2)$. Before 2008, the genus Cronobacter spp. was referred to singularly as Enterobacter sakazakii in the medical literature until it was noted that there was significant variability among the various E. sakazakii isolates. This finding led to their reclassification to the Cronobacter genus (3).

The natural habitats of Cronobacter spp. are predominantly plant and organic material. The pathogen has been isolated from various food sources - cheese, meat, milk powder, powdered infant formula (PIF), infant weaning foods, chocolate, dry cereals, potato flour, fresh and dried herbs and spices, and pasta $(3,4)$. The microorganism has also been isolated from the nasopharynx and gastrointestinal tract of humans, the home environment (e.g., house dust, vacuum cleaner collection bags, and kitchen utensils), hospital environments, flies and rodents, and in PIF manufacturing facilities (4). However, when compared with other members of the Enterobacteriaceae family or with non-fermentative Gram-negative bacilli (e.g., Pseudomonas spp. or Acinetobacter spp.), Cronobacter spp. have rarely been implicated as a significant cause of healthcare-associated infections or outbreaks (5).

\section{Epidemiology of PIF-Associated Cronobacter Infections}

Cronobacter spp. are associated with systemic infection, meningitis, and necrotizing enterocolitis in premature infants. The incidence of infection in the US is reported to be $>9$ infections per 100,000 
neonates of very-low-birth-weight $(4,6,7)$. There are much fewer reported cases of $C$. sakazakii infections in adults with most occurring in persons with malignancies and other debilitating conditions $(8,9)$.

In a comprehensive review of Cronobacter infections documented in Centers for Disease Control and Prevention (CDC), US Food and Drug Administration (FDA), and World Health Organization (WHO) records, peer-reviewed publications, and personal communications from across the globe for the period 1958 through 2010, Jason confirmed the following: (a) neonates were predominantly affected ( $99 \%$ of case-infants $<3$ months of age); (b) $90 \%$ of case-infants had received PIF beforehand; and (c) $>50 \%$ of the infections ascertained during 2004-2014 occurred in the home setting (10).

Friedemann studied $>100$ neonatal Cronobacter spp. infections between 2000 and 2008 and documented a 42\% mortality among neonates with Cronobacter spp. meningitis (11). Among C. sakazakii infant case consultations conducted by CDC during 1998-2005, 92\% of infants for whom information on feeding practices were available had received a PIF product (12).

Before 1994, C. sakazakii was not recognized as a significant cause of neonatal infection and its association with PIF had not yet been established. Since then, a myriad of published reports and studies have identified contaminated PIF as the main risk factor for neonatal Cronobacter spp. infections (10, 12-21). C. sakazakii strains appear to elicit the type 2 immune response, which is known to be inefficient in fighting intracellular infections, and would explain neonatal susceptibility to unique Cronobacter strains (22).

Contamination with Cronobacter spp. is a global issue. For example, Cronobacter spp. have been isolated from PIF in Korea, from salads, vegetables, minced meat, and produce in Thailand, and from feed and grain samples in Australian farms (23-27).

\section{Why PIF is at risk for Cronobacter spp. Contamination?}

Intrinsic contamination of PIF can occur at any stage during manufacture at the factory before distribution of product for retail; extrinsic contamination of product can occur after the factory container is first opened by the user; at any stage of reconstitution through the use of contaminated water, utensils, work surfaces; at the time of feeding (e.g., using contaminated feeding bottles or enteral tubing with existing biofilm); or because of inappropriate storage conditions (e.g., poor refrigeration or storage for too long at room temperature) (7). Underlying all the occurrences (whether at the site of manufacture, or during reconstitution at the hospital, or the home) is unsatisfactory or non-adherence to appropriate infection control practices and procedures.

Because reconstitution of PIF in hot water significantly reduces Cronobacter bioburden, it is believed that the manufacturing phase after pasteurization is the juncture where intrinsic contamination frequently occurs. Contamination of PIF can occur if the plant-derived PIF ingredients are not properly pasteurized with prior heat treatment $(28,29)$. The importance of having a validated pasteurization process for PIF manufacture is underscored by the fact that bioburden levels in contaminated PIF product are generally low (never $>1 \mathrm{cfu} /$ gram $)(3,4,21)$.
Powdered infant formula contamination can occur during the remaining stages in the production process, especially during phases close to the packing of the final product $(30,31)$. Proudy et al. found that the majority $(78 \%)$ of isolates were recovered from processing areas (surfaces around dryers and blenders); $12 \%$ from ingredients and $10 \%$ from final product (31).

Intrinsic properties and survival mechanisms that enable Cronobacter spp. to end up as a PIF contaminant include resistance to desiccation and osmotic stresses (3). The microorganism has a heteropolysaccharide capsule that is resistant to osmotic desiccation. Cronobacter strains can therefore survive for relatively long periods (often $>2$ years) in the desiccated state in PIF and other powdered foods. By contrast, non-capsulated strains have shorter survival spans and are relatively less pathogenic (3).

Cronobacter spp. are also tolerant to acids, a property that renders them resistant to the low $\mathrm{pH}$ environment in the human stomach; some species produce an enterotoxin that is heat-stable and able to survive pasteurization of PIF (16). The microorganism also generates an endotoxin lipopolysaccharide that facilitates the translocation of the bacteria across the intestinal wall and across the blood-brain barrier (4). This endotoxin is heat-stable and able to remain viable for long periods in reconstituted PIF (16).

Sialic acid is an additive to PIF during manufacture because of its reported ability to foster healthy brain development in the neonate (4). C. sakazakii is unique within the Cronobacter genus in that it can utilize sialic acid for growth. This property enables C. sakazakii to remain viable in PIF brands that are both contaminated with the microorganism and fortified with sialic acid.

Cronobacter spp. bacterial cells tend to attach more readily to hydrophobic surfaces, such as Teflon and plastics, than to hydrophilic surfaces, such as glass and metals (16). Thus, if PIF is contaminated with Cronobacter spp. during manufacture, the reconstitution process basically allows formation of a medium that will facilitate bacterial growth, especially if containers and feeding bottles are made of Teflon or plastic materials.

Cronobacter spp. can form biofilms, which render them resistant to high-level disinfection (1). The potential for biofilms to play a key role in the chain of transmission is underscored by the observation that, compared with other Enterobacteriaceae, Cronobacter spp. tend to have the highest biofilm cell density. Several outbreaks of Cronobacter infections abroad and in the US have involved infants who were fed reconstituted PIF via enteral feeding tubes over a period of several hours at ambient temperature $(2,4,21)$. Enteral feeding tubes with biofilms may act as loci for the attachment and multiplication of Cronobacter spp. Thus, organisms will enter the stomach of the neonate whatever type of infusate or feed bolus passes through an enteral tube with a colonized biofilm. This is the likely scenario in the neonatal critical care setting rather than the home.

Multiplication of Cronobacter in the syringe used for introducing reconstituted PIF through the enteral feeding tubes may also cause large numbers of the microorganism to be introduced into the infant, especially if the filled syringe was stored at room temperature after reconstitution (4). For enteral tubes with aged, colonized biofilms, cells shed from the biofilm may survive passage through the neonate's stomach and contribute to the onset of infection $(4,32,33)$. 


\section{Environmental and Product Testing Recommendations}

Food and Drug Administration instituted a method that combines a polymerase chain reaction (PCR) assay in combination with two chromogenic agars that reduce the time needed for identifying the microorganism from 5 to 3 days (23). FDA's end-product testing protocol is based on the presumption that the pathogen is uniformly distributed througout PIF batches deemed to be contaminated with Cronobacter. In fact, Cronobacter spp. tend to be non-homogeneously distributed in PIF by clumping to form spatial clusters in end-product (34). This property limits the utility of random sampling of PIF batches for quality assurance or public health surveillance.

The FDA method recommended for Cronobacter ascertainment has since been revised to combine real-time PCR, chromogenic agars, and RAPID ID 32E biochemical tests for isolation and detection of Cronobacter within $24-48 \mathrm{~h}(35,36)$. For epidemiologic characterization and analyses, PFGE with two restriction enzymes is currently the most commonly used molecular method (37).

\section{Global Surveillance of Cronobacter spp. Infections}

Most serious cases of Cronobacter neonatal infections during the past 30 years have been caused by strains with a highly stable molecular sequence profile (C. sakazakii sequence type 4 or ST4) $(23,38)$. These four distinct pulse-types have been implicated in outbreaks associated with necrotizing enterocolitis, septicemia, or meningitis. Phenotyping schemes and $16 \mathrm{~S}$ rDNA sequence analyses have identified a total of 16 biotypes among Cronobacter spp. (39-44).

However, only one specific pulse-type appears to be associated with significant mortality and the ability to penetrate intestinal and blood-brain barrier cells $(40,41)$. At the present time, molecular typing methods are being increasingly used as a faster and more reliable tool to identify, classify, study genomic diversity, and track sources of infection, and have largely replaced phenotyping methods in the characterization of Cronobacter spp. $(2,44)$.

In 2004, the WHO instituted a molecular typing scheme to enable the international control of the Cronobacter spp. infections. Baldwin and colleagues surmised that sequencing data from multiple gene loci rather than one locus might be better phylogenetic markers and would enable better discrimination between strains compared with $16 \mathrm{~S}$ rDNA sequencing (39). They established a comprehensive genotyping scheme based on multilocus sequence typing (MLST) for Cronobacter spp. The scheme is based on seven gene loci with specific functions, including DNA repair, replication, amino acid biosynthesis, and wide distribution across the chromosome. This led to the establishment of the Cronobacter PubMLST genome and sequence definition database (http://pubmlst.org/Cronobacter/) containing over 1000 isolates and detailed data on specific clonal lineages linked to neonatal meningitis and adult infections $(44,45)$. This database is a central, open access, reliable, sequence-based source for researchers. It enables integration of clinical, epidemiologic, microbiologic, and molecular typing data and retrospective analyses of historic cases and outbreaks. By applying the MLST scheme to over 1000 strains, Forsythe and colleagues identified 298 definable sequence types. Of these 298 strains, only one - C. sakazakii clonal sequence type 4 - again was found to be associated with neonatal meningitis (45). This strain is thought to be a stable clone because it has been identified in seven countries for over 50 years (46).

\section{Prevention of PIF-Associated Cronobacter Infections in Neonates}

Though there are no specific testing recommendations, the Food and Agriculture Organization/World Health Organization (FAO/WHO) established a list of recommendations for hospitals and homes regarding PIF preparation for infants during the first 2 months of life, when the risk of infection is highest $(47,48)$. These recommendations are summarized as follows:

(i) PIF should be reconstituted with hot water $\left(>70^{\circ} \mathrm{C}\right)$ to reduce the Cronobacter spp. vegetative concentration.

(ii) Utensils for formula preparation must be disinfected.

(iii) Reconstituted PIF should be refrigerated at $4^{\circ} \mathrm{C}$ if not used immediately, with disposal if not used within $24 \mathrm{~h}$ of preparation.

(iv) Reconstituted PIF should be kept at room temperature for a maximum of $4 \mathrm{~h}$ if not used immediately, and should never be kept warm in bottle heaters or thermos flasks.

(v) If storage is deemed necessary or unavoidable, it should be at temperatures $<5^{\circ} \mathrm{C}$.

(vi) Hospitals need to establish protocols, in the event of product recall, so that product batch follow-up and accurate data aggregation could be carried out.

Maintenance of enteral feeding tubes in neonates is of paramount importance in the efforts to prevent healthcareassociated adverse events, especially in neonatal intensive care units. Neonatal critical care specialists, infection control preventionists, and hospital epidemiologists need to appreciate the risks associated with biofilm formation in enteral feeding tubes used for neonatal nutrition. Healthcare administrators need to ensure that PIF procured for feeding high-risk infants in their respective facilities is sterile or has undergone a validated sterilization process (23).

Regulatory standards for infant food manufacturers need to be improved. Yan et al. recommend effective environmental monitoring programs, good manufacturing practice guidelines, and procedures and hazard analysis and critical control point (HACCP) systems to control the risk of microbiological contamination along the entire production chain, from the starting raw materials, throughout the entire process, until the final product is ready for distribution (23). PIF manufacturers also need to improve the labeling of PIF products and communication with consumers to enhance awareness of the correct methods for reconstituting PIF products. Education of healthcare professionals to help them provide quality training for parents and caregivers in PIF preparation, handling, and storage is particularly 
important for economically less-developed countries, where PIF use is relatively common.

In conclusion, adherence to regulatory standards by PIF producers and to FAO/WHO guidelines for PIF reconstitution and

\section{References}

1. Chenu JW, Cox JM. Cronobacter ('Enterobacter sakazakii'): current status and future prospects. Lett Appl Microbiol (2009) 49(2):153-9. doi:10.1111/j. 1472-765X.2009.02651.x

2. Caubilla-Barron J, Hurrell E, Townsend S, Cheetham P, Loc-Carrillo C, Fayet O, et al. Genotypic and phenotypic analysis of Enterobacter sakazakii strains from an outbreak resulting in fatalities in a neonatal intensive care unit in France. $J$ Clin Microbiol (2007) 45(12):3979-85. doi:10.1128/JCM.01075-07

3. Osaili T, Forsythe S. Desiccation resistance and persistence of Cronobacter species in infant formula. Int J Food Microbiol (2009) 136(2):214-20. doi:10. 1016/j.ijfoodmicro.2009.08.006

4. Holy O, Forsythe S. Cronobacter spp. as emerging causes of healthcareassociated infection. J Hosp Infect (2014) 86(3):169-77. doi:10.1016/j.jhin.2013. 09.011

5. Archibald LK, Jarvis WR. Health care-associated infection outbreak investigations by the centers for disease control and prevention, 1946-2005. Am J Epidemiol (2011) 174(11 Suppl):S47-64. doi:10.1093/aje/kwr310

6. Stoll BJ, Hansen N, Fanaroff AA, Lemons JA. Enterobacter sakazakii is a rare cause of neonatal septicemia or meningitis in VLBW infants. J Pediatr (2004) 144(6):821-3. doi:10.1016/S0022-3476(04)00175-1

7. Hunter CJ, Bean JF. Cronobacter: an emerging opportunistic pathogen associated with neonatal meningitis, sepsis and necrotizing enterocolitis. J Perinatol (2013) 33(8):581-5. doi:10.1038/jp.2013.26

8. Corti G, Panunzi I, Losco M, Buzzi R. Postsurgical osteomyelitis caused by Enterobacter sakazakii in a healthy young man. J Chemother (2007) 19(1):94-6. doi:10.1179/joc.2007.19.1.94

9. Lai KK. Enterobacter sakazakii infections among neonates, infants, children, and adults. Case reports and a review of the literature. Medicine (2001) 80(2):113-22. doi:10.1097/00005792-200103000-00004

10. Jason J. Prevention of invasive Cronobacter infections in young infants fed powdered infant formulas. Pediatrics (2012) 130(5):e1076-84. doi:10.1542/peds. 2011-3855

11. Friedemann M. Epidemiology of invasive neonatal Cronobacter (Enterobacter sakazakii) infections. Eur J Clin Microbiol Infect Dis (2009) 28(11):1297-304. doi:10.1007/s10096-009-0779-4

12. Bowen $\mathrm{AB}$, Braden $\mathrm{CR}$. Invasive Enterobacter sakazakii disease in infants. Emerg Infect Dis (2006) 12(8):1185-9. doi:10.3201/eid1208.051509

13. Urmenyi AM, Franklin AW. Neonatal death from pigmented coliform infection. Lancet (1961) 1(7172):313-5. doi:10.1016/S0140-6736(61)91481-7

14. Kandhai MC, Reij MW, Gorris LG, Guillaume-Gentil O, van Schothorst M. Occurrence of Enterobacter sakazakii in food production environments and households. Lancet (2004) 363(9402):39-40. doi:10.1016/S0140-6736(03) 15169-0

15. Clark NC, Hill BC, O’Hara CM, Steingrimsson O, Cooksey RC. Epidemiologic typing of Enterobacter sakazakii in two neonatal nosocomial outbreaks. Diagn Microbiol Infect Dis (1990) 13(6):467-72. doi:10.1016/0732-8893(90)90078-A

16. Jaradat ZW, Al Mousa W, Elbetieha A, Al Nabulsi A, Tall BD. Cronobacter spp. - opportunistic food-borne pathogens. A review of their virulence and environmental-adaptive traits. J Med Microbiol (2014) 63(Pt 8):1023-37. doi:10. 1099/jmm.0.073742-0

17. Muytjens HL, Roelofs-Willemse H, Jaspar GH. Quality of powdered substitutes for breast milk with regard to members of the family Enterobacteriaceae. J Clin Microbiol (1988) 26(4):743-6.

18. Osaili TM, Shaker RR, Ayyash MM, Al-Nabulsi AA, Forsythe SJ. Survival and growth of Cronobacter species (Enterobacter sakazakii) in wheat-based infant follow-on formulas. Lett Appl Microbiol (2009) 48(4):408-12. doi:10.1111/j. 1472-765X.2008.02541.x

19. Siqueira Santos RF, da Silva N, Amstalden Junqueira VC, Kajsik M, Forsythe S, Pereira JL. Screening for Cronobacter species in powdered and reconstituted infant formulas and from equipment used in formula preparation in maternity hospitals. Ann Nutr Metab (2013) 63(1-2):62-8. doi:10.1159/000353137 storage by consumers, and continuing surveillance and educational activities by CDC, FDA, and WHO are essential for the prevention of PIF-associated Cronobacter infections and other opportunistic pathogens in neonates.

20. Cawthorn DM, Botha S, Witthuhn RC. Evaluation of different methods for the detection and identification of Enterobacter sakazakii isolated from South African infant formula milks and the processing environment. Int $\mathrm{J}$ Food Microbiol (2008) 127(1-2):129-38. doi:10.1016/j.ijfoodmicro.2008.06.024

21. Centers for Disease Control and Prevention. Enterobacter sakazakii infections associated with the use of powdered infant formula-Tennessee, 2001. JAMA (2002) 287(17):2204-5. doi:10.1001/jama.287.17.2204

22. Townsend SM, Hurrell E, Gonzalez-Gomez I, Lowe J, Frye JG, Forsythe S, et al. Enterobacter sakazakii invades brain capillary endothelial cells, persists in human macrophages influencing cytokine secretion and induces severe brain pathology in the neonatal rat. Microbiology (2007) 153(Pt 10):3538-47. doi:10. 1099/mic.0.2007/009316-0

23. Yan QQ, Condell O, Power K, Butler F, Tall BD, Fanning S. Cronobacter species (formerly known as Enterobacter sakazakii) in powdered infant formula: a review of our current understanding of the biology of this bacterium. J Appl Microbiol (2012) 113(1):1-15. doi:10.1111/j.1365-2672.2012.05281.x

24. Kim SA, Oh SW, Lee YM, Imm JY, Hwang IG, Kang DH, et al. Microbial contamination of food products consumed by infants and babies in Korea. Lett Appl Microbiol (2011) 53(5):532-8. doi:10.1111/j.1472-765X.2011.03142.x

25. Beuchat LR, Kim H, Gurtler JB, Lin LC, Ryu JH, Richards GM. Cronobacter sakazakii in foods and factors affecting its survival, growth, and inactivation. Int J Food Microbiol (2009) 136(2):204-13. doi:10.1016/j.ijfoodmicro.2009.02.029

26. Ananchaipattana C, Hosotani Y, Kawasaki S, Pongsawat S, Latiful BM, Isobe $\mathrm{S}$, et al. Prevalence of foodborne pathogens in retailed foods in Thailand. Foodborne Pathog Dis (2012) 9(9):835-40. doi:10.1089/fpd.2012.1169

27. Molloy C, Cagney C, O'Brien S, Iversen C, Fanning S, Duffy G. Surveillance and characterisation by pulsed-field gel electrophoresis of Cronobacter spp. in farming and domestic environments, food production animals and retail foods. Int J Food Microbiol (2009) 136(2):198-203. doi:10.1016/j.ijfoodmicro. 2009.07.007

28. Mullane NR, Whyte P, Wall PG, Quinn T, Fanning S. Application of pulsedfield gel electrophoresis to characterise and trace the prevalence of Enterobacter sakazakii in an infant formula processing facility. Int J Food Microbiol (2007) 116(1):73-81. doi:10.1016/j.ijfoodmicro.2006.12.036

29. Healy B, Cooney S, O'Brien S, Iversen C, Whyte P, Nally J, et al. Cronobacter (Enterobacter sakazakii): an opportunistic foodborne pathogen. Foodborne Pathog Dis (2010) 7(4):339-50. doi:10.1089/fpd.2009.0379

30. Reich F, Konig R, von Wiese W, Klein G. Prevalence of Cronobacter spp. in a powdered infant formula processing environment. Int J Food Microbiol (2010) 140(2-3):214-7. doi:10.1016/j.ijfoodmicro.2010.03.031

31. Proudy I. [Enterobacter sakazakii in powdered infant food formulas]. Can J Microbiol (2009) 55(5):473-500. doi:10.1139/W08-131

32. Hurrell E, Kucerova E, Loughlin M, Caubilla-Barron J, Forsythe SJ. Biofilm formation on enteral feeding tubes by Cronobacter sakazakii, Salmonella serovars and other Enterobacteriaceae. Int J Food Microbiol (2009) 136(2):227-31. doi:10. 1016/j.ijfoodmicro.2009.08.007

33. Hurrell E, Kucerova E, Loughlin M, Caubilla-Barron J, Hilton A, Armstrong R, et al. Neonatal enteral feeding tubes as loci for colonisation by members of the Enterobacteriaceae. BMC Infect Dis (2009) 9:146. doi:10.1186/1471-2334-9-146

34. Jongenburger I, Jongenburger I, Reij MW, Boer EPJ, Gorris LGM, Zwietering MH. Actual distribution of Cronobacter spp. in industrial batches of powdered infant formula and consequences for performance of sampling strategies. Int $J$ Food Microbiol (2011) 151(1):62-9. doi:10.1016/j.ijfoodmicro.2011.08.003

35. Chen Y, Noe KE, Thompson S, Elems CA, Brown EW, Lampel KA, et al. Evaluation of a revised U.S. food and drug administration method for the detection of Cronobacter in powdered infant formula: a collaborative study. J Food Prot (2012) 75(6):1144-7. doi:10.4315/0362-028X.JFP-11-388

36. Lampel KA, Chen Y. Method for the isolation and detection of Enterobacter sakazakii (Cronobacter) from powdered infant formula. Int J Food Microbiol (2009) 136(2):179-84. doi:10.1016/j.ijfoodmicro.2009.08.016

37. Brengi SP, O’Brien SB, Pichel M, Iversen C, Arduino M, Binsztein N, et al. Development and validation of a PulseNet standardized protocol for subtyping 
isolates of Cronobacter species. Foodborne Pathog Dis (2012) 9(9):861-7. doi:10. 1089/fpd.2012.1161

38. Hariri S, Joseph S, Forsythe SJ. Cronobacter sakazakii ST4 strains and neonatal meningitis, United States. Emerg Infect Dis (2013) 19(1):175-7. doi:10.3201/ eid1901.120649

39. Baldwin A, Loughlin M, Caubilla-Barron J, Kucerova E, Manning G, Dowson C, et al. Multilocus sequence typing of Cronobacter sakazakii and Cronobacter malonaticus reveals stable clonal structures with clinical significance which do not correlate with biotypes. BMC Microbiol (2009) 9:223. doi:10.1186/ 1471-2180-9-223

40. Townsend S, Hurrell E, Forsythe S. Virulence studies of Enterobacter sakazakii isolates associated with a neonatal intensive care unit outbreak. BMC Microbiol (2008) 8:64. doi:10.1186/1471-2180-8-64

41. Kucerova E, Clifton SW, Xia XQ, Long F, Porwollik S, Fulton L, et al. Genome sequence of Cronobacter sakazakii BAA-894 and comparative genomic hybridization analysis with other Cronobacter species. PLoS One (2010) 5(3):e9556. doi:10.1371/journal.pone.0009556

42. Iversen C, Waddington M, On SL, Forsythe S. Identification and phylogeny of Enterobacter sakazakii relative to Enterobacter and Citrobacter Species. J Clin Microbiol (2004) 42(11):5368-70. doi:10.1128/JCM.42.11.5368-5370.2004

43. Iversen C, Waddington M, Farmer JJ III, Forsythe SJ. The biochemical differentiation of Enterobacter sakazakii genotypes. BMC Microbiol (2006) 6:94. doi:10.1186/1471-2180-6-94

44. Joseph S, Forsythe SJ. Insights into the emergent bacterial pathogen Cronobacter spp., generated by multilocus sequence typing and analysis. Front Microbiol (2012) 3:397. doi:10.3389/fmicb.2012.00397
45. Forsythe SJ, Dickins B, Jolley KA. Cronobacter, the emergent bacterial pathogen Enterobacter sakazakii comes of age; MLST and whole genome sequence analysis. BMC Genomics (2014) 15:1121. doi:10.1186/1471-2164-15-1121

46. Joseph S, Forsythe SJ. Predominance of Cronobacter sakazakii sequence type 4 in neonatal infections. Emerg Infect Dis (2011) 17(9):1713-5. doi:10.3201/eid1709. 110260

47. Codex Alimentarius Commission (CAC). Code of Hygienic Practice for Powdered Formulae for Infants and Young Children (CAC/RCP 66-2008). Rome: Joint FAO/WHO Food Standards Programme (2008).

48. Giovannini M, Verduci E, Ghisleni D, Salvatici E, Riva E, Agostoni C. Enterobacter sakazakii: an emerging problem in paediatric nutrition. J Int Med Res (2008) 36(3):394-9. doi:10.1177/147323000803600303

Conflict of Interest Statement: None of the authors have any conflict of interest or financial disclosures. In addition, none of the authors received any financial remuneration for writing this manuscript. Dr. Lennox Kenneth Archibald is the Hospital Epidemiologist at the Malcom Randall Veterans Administration Medical Center, a US Government medical facility for military veterans. The opinions in this paper are solely those of the authors and do not reflect the opinion of the US Government.

Copyright $\odot 2015$ Kalyantanda, Shumyak and Archibald. This is an open-access article distributed under the terms of the Creative Commons Attribution License (CC $B Y)$. The use, distribution or reproduction in other forums is permitted, provided the original author(s) or licensor are credited and that the original publication in this journal is cited, in accordance with accepted academic practice. No use, distribution or reproduction is permitted which does not comply with these terms. 